\title{
Prioritizing the reasons for non-moving inventory accumulation in FMCG industry: A MCDM based TOPSIS Approach
}

\author{
Lakshman Singh Negi', Yashomandira Kharde ${ }^{2}$ \\ ${ }^{1}$ Symbiosis Institute of Operations Management, Nashik, Symbiosis International (Deemed University), Pune, India \\ ${ }^{2}$ Professor, Symbiosis Institute of Operations Management, Nashik, Symbiosis International (Deemed University), Pune, India
}

\begin{abstract}
Generation of Non-moving inventory (NMI) in any industry is an annoyance for the people involved, as it occupies the storage space that is limited and also blocks company's capital that gets stuck in the form of material cost. These Non-moving inventory, if identified at earlier stage can be beneficial for any business, as some preventive actions can be taken to prevent its distressing affect. This generally starts with a slow moving inventory and then gradually translate to Non-moving inventory. This research aims to examine the potential causes for the accumulation of Non-moving inventory in the FMCG industry and their contribution towards the factors like Inventory carrying cost, Quantity left over in inventory, effect on labor productivity, loss of opportunity cost and storage space have been analyzed. The causes for generation of NMI are identified from survey data collection such as questionnaire approach and discussion from industry experts and managers working in different FMCG industries. After the identification of probable causes for non-moving inventory creation, they are analyzed through a Multicriterion decision making (MCDM) approach, TOPSIS to find out the major contributor for the NMI in the FMCG industry. With the help of MCDM tool, TOPSIS we then prioritize the potential causes and take corrective actions to prevent their disruptive effect on the business.
\end{abstract}

Keywords

Non-moving inventory (NMI), FMCG Industry, Multi-criteria decision making (MCDM), Euclidean distance, best ideal solution, worst ideal solution, TOPSIS

Article Received: 10 August 2020, Revised: 25 October 2020, Accepted: 18 November 2020

\section{Introduction}

Non-moving inventory is a major problem for any company as not only it occupies the valuable storage space but it also blocks your company's capital and now you are available with less cash to run your company's business. Accumulation of non-moving inventory in any organization contribute towards Inventory carrying cost, it affects your labor productivity, increases your equipment expenses and there is loss of opportunity associated with it. Therefore, it is essential for any organization to come up with solution to deal with this non-moving inventory.

There are several reasons involved for a product category such as raw material, bought out part, finished good or semifinished good to become a part of non-moving inventory and get accumulated in the spares inventory. Few of the reasons for NMI identified from the discussion with the managers and industry experts are listed below:

1. Sales/ forecasting error - In anticipation of demand sometimes over forecasting is done and if order is not received as per the projections, it leads to NMI

2. Procurement of wrong part/ material Sometimes procurement of wrong part or material from the supplier leads to NMI as this material has to be stocked till similar order comes.

3. System entry error - Due to error in data entry, you procure excess material which leads to accumulation of NMI. This error occurs due to two reasons; material is being consumed but entry is pending in system or material is available but system is not showing.

4. Material purchased in bulk - To get the price benefit from the order, material is being procured in bulk than the actual requirement and it creates NMI in the system 5. Defects in production/ Quality related issue -
Customer rejects the material, if there is defects due to manufacturing or quality issues, then this material has to be stocked and it creates NMI.

6. Order change/ Specification change - In some situations due to variation and fluctuations in demand pattern customer change the order or the specifications after the procurement of material, this leads to accumulation of NMI

7. Inventory methods not followed i.e. FIFO - It happens that due to time commitment for some orders, inventory methods like FIFO is ignored either from production team or from dispatch team, thus leading to generation of NMI

8. Communication gap - Due to communication gap between supplier, planner and marketing, leads to procurement of wrong material, purchase of excess material and production of surplus goods, all these leads to NMI

9. Product category not traceable - Due to mismanagement of inventory, we are unable to trace a particular product category when customer orders the same. So, you go on buying that extra material and that leads to NMI

\section{Literature Review}

Non-moving inventory is a serious headache for any industry professional. According to [Braglia, Grassi and Montanari (2004)], Non-moving inventory also known as dead inventory are the materials that get stuck in the inventory either due to slowdown in demand or consumption pattern or due to some defects in production or quality related issues. As these inventory has a cost associated with it, in terms of material cost, organization have to stockpile these NMI in a hope to recover their 
material cost that is cling with these items. In 2003 [Wintle and patch (2003)] had argued that your organizational policies, your competitive priorities, your support system and your training of staff, leads an organization to stock inappropriate quantities of Non-moving inventory in the system.

Moreover, holding unwanted inventory or excess inventory in an organization is always a costly affair, according to [Ferderick Hiller and Gerald Lieberman (2007)], various cost connected with slow moving inventory or bad inventory levels are: increasing labor cost in various inventory activities, extra equipment expenses and the cost of maintenance of an equipment, insurance cost in form of premiums, loss of opportunity cost and the cost associated with detention of materials. So, in order to avoid all these unnecessary costs associated with extra inventory in the system, it is necessary to have a proper inventory management system in the company. [Ganeshan (1999)], discussed that inventory management is an important aspect for any organization and optimum inventory level should be maintain to have an economic sense for the organization, as inventory can cost a company from about $20 \%$ to $40 \%$ of the total inventory value throughout the year, so it should be properly checked and maintained at a minimal level as per the requirements of the company.

In the view of [Romanies (2016)], holding non-moving inventory or bad inventory for a long period of time without scrapping or disposing it, will lead to a significant amount of cost for any organization, in terms of loss of other investment opportunities, excess cost associated with storing and managing the items and increment in the management costs along with more financial expenses. So, with this study we are trying to find out the major contributor towards the accumulation of non-moving inventory in the FMCG industry and for carrying out our analysis, we are using approach of Multi-criterion decision making and using TOPSIS as a tool to proceed further.

Among several Multi-criterion decision making approaches available with us, TOPSIS is the most commonly used approach for making decision. TOPSIS (Technique for order preference by similarity to ideal solution) was first proposed by [Hwang and Yoon (1981)] as a method for ranking alternatives on the basis of certain attribute and criteria by using the shortest distance approach i.e. Euclidean distance from ideal solution. This technique was later developed by many authors [Jahanshahloo, Lofti, Izadikhah (2006a)] who presented steps and procedures, for doing TOPSIS analysis for multi criteria decision making. If qualitative criteria or attribute are there it has to be converted into linguistic variables using a rating point scale system where the ratings vary from 1 to 9, [Jadidi, Hong, Firouzi, Yusuff, Zulkifli (2008)]

\section{Methodology}

First the potential factors for accumulation of Non-Moving inventory in the FMCG industry are identified from the survey data collection and discussions with managers and executives and then the weights are assigned to attributes and criteria to study effects for these factors. For carrying out this study a total of 9 potential causes were identified and the contribution of these 9 causes on 5 attributes or criteria i.e. Quantity (in tons), Holding and Carrying cost, Effect on labor productivity, loss of opportunity cost and storage space were identified. These 5 attributes were given weights of $0.25,0.30,0.15,0.10,0.20$ respectively. These weights for the attributes were given after discussion with the experts. After identification of the causes and their respective contribution towards the generation of Nonmoving inventory, a MCDM tool i.e. TOPSIS is being used to prioritize the severity of these causes towards accumulation of non-moving inventory. For carrying out TOPSIS analysis six main steps are followed that are listed below:

Step 1: Formulation of Normalized decision matrix

Step 2: Formulation of Weighted Normalized decision matrix, by multiplying each performance score by weights of the criteria.

Step 3: Identification of Ideal best i.e. $\mathrm{N}_{\mathrm{j}}^{+}$and Ideal worst i.e. $\mathrm{N}_{\mathrm{j}}{ }^{-}$solution.

Step 4: Identification of Euclidean distance from ideal best i.e. $\mathrm{Ki}^{+}$and ideal worst i.e. $\mathrm{Ki}^{-}$solution.

Step 5: Calculate performance score i.e. $X_{i}$

Step 6: Rank the potential causes based on their performance score

\section{Data Analysis}

Here, $\mathrm{Cij}$ denotes the performance value and this is the value gathered from survey data analysis through questionnaire approach and discussion with the industry experts. These values are shown in the Table 1 below:

Table 1: Performance score of each causes wrt. attributes or criteria

\begin{tabular}{|c|c|c|c|c|c|}
\hline Potential Causes Contribution to & $\begin{array}{l}\text { Quantity } \\
\text { (Tons) }\end{array}$ & $\begin{array}{l}\text { Holding I } \\
\text { carrying } \\
\text { cost (Rs.) }\end{array}$ & \begin{tabular}{|c|} 
Effect on \\
labor \\
productivity
\end{tabular} & \begin{tabular}{|c|} 
Loss of \\
Opportunity \\
Cost
\end{tabular} & $\begin{array}{l}\text { Excess } \\
\text { Storage } \\
\text { space }\end{array}$ \\
\hline Sales / Forecasting error & 75 & 350000 & 5 & 6 & 7 \\
\hline Procurement of wrong part/ material & 60 & 159000 & 8 & 9 & 8 \\
\hline System Entry Error & 15 & 120000 & 9 & 8 & 6 \\
\hline Material purchased in Bulk & 35 & 90000 & 6 & 6 & 6 \\
\hline $\begin{array}{l}\text { Defects in Production / Quality related } \\
\text { Issue }\end{array}$ & 13 & 250000 & 8 & 9 & 9 \\
\hline Order change / Specification change & 32 & 200000 & 7 & 9 & 9 \\
\hline Inventory methods not followed i.e., FIFO & 48 & 75000 & 6 & 7 & 8 \\
\hline Communication gap b/w departments & 35 & 60000 & 7 & 8 & 7 \\
\hline Product category not traceable & 52 & 90000 & 9 & 8 & 7 \\
\hline Rooted summation of sq. values & 134.54 & 538614.89 & 22.02 & 23.58 & 22.56 \\
\hline
\end{tabular}

For the qualitative values, for which the expression in number format or quantitative terms is not possible, we convert them into linguistic values using a rating scale that varies from 1 to 9 as shown below and giving them weightage according to the criteria to carry out our analysis.

\begin{tabular}{|c|c|}
\hline 1 & Very Weak \\
\hline 3 & Weak \\
\hline 5 & Moderate \\
\hline 7 & Strong \\
\hline 9 & Very Strong \\
\hline $2,4,6,8$ & Intermediate \\
\hline
\end{tabular}


Fig 1: This is the linguistic scale used for qualitative values After that we find the Normalized decision matrix by dividing performance value with rooted summation of square values using the formula as shown. The normalized decision matrix is presented in the Table 2:

\section{Normalized Decision Matrix}

\begin{tabular}{|c|c|c|c|c|c|}
\hline Weightage & 0.25 & 0.30 & 0.15 & 0.10 & 0.20 \\
\hline Potential Causes Contribution to & $\begin{array}{l}\text { Quantity } \\
\text { (Tons) }\end{array}$ & $\begin{array}{l}\text { Holding I } \\
\text { carrying } \\
\text { cost (Rs.) }\end{array}$ & $\begin{array}{l}\text { Effect on } \\
\text { labor } \\
\text { productivity }\end{array}$ & $\begin{array}{l}\text { Loss of } \\
\text { Opportunity } \\
\text { Cost }\end{array}$ & $\begin{array}{c}\text { Excess } \\
\text { Storage } \\
\text { space }\end{array}$ \\
\hline Sales / Forecasting error & 0.557 & 0.650 & 0.227 & 0.254 & 0.310 \\
\hline Procurement of wrong part/ material & 0.446 & 0.295 & 0.363 & 0.382 & 0.355 \\
\hline System Entry Error & 0.111 & 0.223 & 0.409 & 0.339 & 0.266 \\
\hline Material purchased in Bulk & 0.260 & 0.167 & 0.272 & 0.254 & 0.266 \\
\hline $\begin{array}{c}\text { Defects in Production/ Quality related } \\
\text { Issue }\end{array}$ & 0.097 & 0.464 & 0.363 & 0.382 & 0.399 \\
\hline Order change/ Specification change & 0.238 & 0.371 & 0.318 & 0.382 & 0.399 \\
\hline Inventory methods not followed i.e., FIFO & 0.357 & 0.139 & 0.272 & 0.297 & 0.355 \\
\hline Communication gap b/w departments & 0.260 & 0.111 & 0.318 & 0.339 & 0.310 \\
\hline Product category not traceable & 0.387 & 0.167 & 0.409 & 0.339 & 0.310 \\
\hline
\end{tabular}

Table 2: Normalized Decision Matrix

Then we give weightage to each of the selected criteria's as shown in Table 2 and then proceed further to find the weighted normalized decision matrix as presented in Table 3 .

\section{Weighted Normalized Decision Matrix}

\begin{tabular}{|c|c|c|c|c|c|c|c|c|c|c|}
\hline Potential Causes & $\begin{array}{l}\text { Quantity } \\
\text { (Tons) }\end{array}$ & $\begin{array}{l}\text { Holding/ } \\
\text { carrying } \\
\text { cost } \\
\text { (Rs.) }\end{array}$ & $\begin{array}{l}\text { Effect on } \\
\text { labor } \\
\text { producti } \\
\text { vity }\end{array}$ & $\begin{array}{l}\text { Loss of } \\
\text { Opportunity } \\
\text { Cost }\end{array}$ & $\begin{array}{l}\text { Excess } \\
\text { Storage } \\
\text { space }\end{array}$ & $\mathbf{K}_{\mathbf{i}}+$ & $\mathbf{K}_{\mathbf{i}}-$ & $\begin{array}{c}\left(\mathrm{K}_{\mathrm{i}}+\right) \\
+ \\
\left(\mathrm{K}_{\mathrm{i}-}\right)\end{array}$ & $\mathrm{x}_{\mathrm{i}}$ & Rank \\
\hline Sales / Forecasting error & 0.139 & 0.195 & 0.034 & 0.025 & 0.062 & 0.035 & 0.199 & 0.234 & 0.851 & 1 \\
\hline $\begin{array}{l}\text { Procurement of wrong } \\
\text { part / material }\end{array}$ & 0.111 & 0.089 & 0.054 & 0.038 & 0.071 & 0.111 & 0.108 & 0.218 & 0.493 & 2 \\
\hline System Entry Error & 0.028 & 0.067 & 0.061 & 0.034 & 0.053 & 0.172 & 0.044 & 0.216 & 0.204 & 8 \\
\hline Material purchased in Bulk & 0.065 & 0.050 & 0.041 & 0.025 & 0.053 & 0.167 & 0.045 & 0.211 & 0.211 & 7 \\
\hline $\begin{array}{l}\text { Defects in Production / } \\
\text { Quality related Issue }\end{array}$ & 0.024 & 0.139 & 0.054 & 0.6. & 80 & 0.128 & 0.112 & 240 & 0.466 & 3 \\
\hline $\begin{array}{l}\text { Order change I } \\
\text { Specification change }\end{array}$ & 0.059 & 0.111 & 0.048 & 0.038 & 0.080 & 0.116 & 0.092 & 0.208 & 0.440 & 4 \\
\hline $\begin{array}{l}\text { Inventory methods not } \\
\text { followed i.e., FIFO }\end{array}$ & 0.089 & 0.042 & 0.041 & 0.030 & 0.071 & 0.163 & 0.068 & 0.231 & 0.296 & 6 \\
\hline $\begin{array}{c}\text { Communication gap b/w } \\
\text { departments }\end{array}$ & 0.065 & 0.033 & 0.048 & 0.034 & 0.062 & 0.179 & 0.045 & 0.224 & 0.200 & 9 \\
\hline $\begin{array}{l}\text { Product category not } \\
\text { traceable }\end{array}$ & 0.097 & 0.050 & 0.061 & 0.034 & 0.062 & & & & 0.345 & 5 \\
\hline
\end{tabular}

Table 3: Weighted Normalized Decision Matrix

For getting Weighted Normalized decision matrix, we first found out $\mathbf{N}_{\mathbf{j}}{ }^{+}$and $\mathbf{N}_{\mathbf{j}}{ }^{-}$which denotes ideal best and ideal worst solution respectively. After that we proceed further to find out $\mathbf{K i}^{+}$and $\mathbf{K i}{ }^{-}$which denotes the Euclidean distance from ideal best and ideal worst solution. To find out $\mathbf{K i}^{+}$ and $\mathbf{K i}^{-}$, we use the following formulas:

$$
\begin{aligned}
& \mathbf{K i}+=\sqrt{\sum_{i=1}^{\mathrm{n}}\left(\mathrm{Nj}^{+}-\mathbf{N i j}\right)^{2}} \\
& \mathbf{K i}-=\sqrt{\sum_{i=1}^{\mathrm{n}}\left(\mathrm{Nj}^{-}-\mathbf{N i j}\right)^{2}}
\end{aligned}
$$

After calculating the $\mathrm{Ki}+$ and $\mathrm{Ki}-$, we proceed further to find out the values of $\mathbf{X}_{\mathbf{i}}$, which is the performance score and it is calculated using the formula given by:

$$
\mathrm{X}_{\mathbf{i}}=\frac{(\mathbf{K i}-)}{(\mathbf{K i}-)+(\mathbf{K i}+)}
$$

On the basis of performance score we rank the alternatives and prioritize them to find out the major contributor of the non-moving inventory.

\section{Results}

On the basis of TOPSIS we first prioritize the major reasons responsible for the accumulation of non-moving inventory in the FMCG industry and then take corrective actions on these causes to reduce our non-moving inventory generation in the company. The top three causes identified from the TOPSIS analysis are Error due to sales \& forecasting, Procurement of wrong part or material and Defects in manufacturing \& Quality related issues. On the basis of this analysis we can work on these major contributors and proceed on our goal to reduce the Non-moving inventory in the organization and the cost incurred by them. Firstly, we focus on these major contributors identified from the TOPSIS analysis for reducing the non-moving inventory in the company and then we move forward towards other contributors.

\section{Conclusions}

As the major contributors for the generation of Non-moving inventory are identified from Multi-criterion decision making approach, TOPSIS. So, to reduce the harmful effect of these non-moving inventory in the company, several measures should be taken care from time to time.

If you have defective product or quality rejected material stacked in your warehouse, it should be either scrapped or sold as disposal. However, the good parts or materials should be either sent to other plants for consumption or should be return back to the supplier. If there is some order change or specification change from the customer end and you have already procured the material, the existing material should be either consumed in other jobs by extra trim wastage or should be sent to other plant that require material with similar specification. Sometimes remains from the left out part also creates dead inventory in the company, so, these materials should be sold as disposal and avoid being stored in your warehouses. As over forecasting in the anticipation of future orders always leads to accumulation of excess raw material, excess finished goods in the system, you should frequently review your forecast in order to avoid unnecessary buildup of inventory in the warehouses. The company should have a proper provision for inventory management system, as mismanagement will lead to accumulation of non-moving inventory in the company. Bulk purchase in order to get the price benefit with respect to order should be avoided as it always ends up in creating excess inventory in the company. Timely and error-free entry should be made in the system and the production \& warehouse personals should be made aware of the harmful effects of non-moving inventory in the company and also the cost incurred by them. Thus, by analyzing on all these 
characteristics and taking corrective actions on all these aspects it is possible for an organization to reduce the accumulation of Non- moving inventory and also the cost experienced by them.

\section{References}

[1] Hwang, C.L., and Yoon, K. (1981), Multiple Attribute Decision Making: Methods \& Applications, Berlin Heidelberg New York, Springer-Verlag.

[2] Ganeshan, R. (1999), Managing supply chain inventories: A multiple retailer, one warehouse, multiple supplier model, "International Journal of Production Economics", 59 (1-3), 341-354.

[3] Braglia, A., Grassi, A., and Montanari, R. (2004), Multi-attribute classification method for spare parts inventory management, "Journal of Quality in maintenance Engineering", 10(1), 55-65.

[4] Deng, H., Yeh, C.H., Willis, R.J. (2000), Inter-company comparison using modified TOPSIS with objective weights, "Computers and Operations Research", 27, $963-973$

[5] Vimal J., Chaturverdi V., Dubey A.K. (2012), Application of TOPSIS method for supplier selection in manufacturing industry, "International Journal of Research in Engineering and Applied Sciences", 2(5), 25 - 35

[6] Romanies, M. (2016), Disposing of obsolete and excess inventory could be your most profitable sale.

[https://www.allbusiness.com/disposing-ofobsolete-and-excess-inventory-could-beyour-most-profitable-sale-116615371.html]

[7] Vaz, A. and Mansori, S. (2017), Target Days versus Actual Days of Finished Goods Inventory in Fast Moving Consumer Goods, "International Business Research", Vol. 10, No. 6; pg. 19-34

[8] Jadidi O., Hong T.S., Firouzi F., Yusuff R.M., Zulkifli N. (2008), TOPSIS and Fuzzy Multi-Objective Model Integration for Supplier Selection Problem, "Journal of Achievements in Materials and Manufacturing Engineering”, 31(2), pp. 762-769

[9] Bala, M., Kumar, D. (2011), Supply chain performance attributes for fast moving consumer goods industry, "Journal of Transport and Supply Chain Management", Vol.5, No. 1, pp. 23-38.

[10] Balaji, K. and Kumar, V.S. (2013), Effects of Slow Moving Inventory in Industries: Insights of Other Researchers, "International Journal of Trade, Economics and Finance", Vol. 4, No. 4

[11] Jadidi O., Hong T.S., Firouzi F., Yusuff R.M. (2008), An Optimal Grey Based Approach Based on TOPSIS Concept for Supplier Selection Problem, "International Journal of Management Science and Engineering Management", Vol. 4, No. 2, pp. 104-117

[12] Vereecke, A. and Verstraeten, P. (1994), An inventory management model for an inventory consisting of lumpy items, slow movers and fast movers, "International Journal of Production Economics", vol. 35, pp. 379-389.

[13] Synder, R. (2002), Forecasting sales of slow and fast moving inventories. "European Journal of Operational Research", vol. 140, pp. 684-699.

[14] Jahanshahloo G.R., Lofti F.H., Izadikhah M. (2006a), An Algorithmic Method to Extend TOPSIS for Decision Making Problems with Interval Data. "Applied Mathematics and Computation”, 175, pp. 1375-1384.

[15] Johnston, F.R., Boylan, J.E., and Shale, E.A. (2003), An examination of the size of orders from customers, their characterization and the implications for inventory control of slow moving items, "The Journal of the Operational Research Society", vol. 54, no. 8, pp. 833-837.

[16] Jahanshahloo G.R., Lofti F.H., Izadikhah M. (2006b), Extension of the TOPSIS Method for Decision-Making Problems with Fuzzy Data. "Applied Mathematics and Computation”, 181, pp. 1544-1551. 
[17] Wintle, F. and Patch, W. (2003), Slowmoving inventory: All Dressed up and nowhere to go, [https://www.inboundlogistics.com/cms/ar ticle/slow-moving-inventory-all-dressedup-and-nowhere-to-go/]

[18] Hahn, G.J. and Leucht, A. (2015), Managing Inventory Systems of SlowMoving Items, "International Journal of Production Economics", v. 170, pp. 543550.

[19] Crandall, R.E. and Crandall, W.R. (2003), Managing excess inventories: A life-cycle approach, "Academy of Management Perspectives", Vol. 17, No. 3

[20] Chopra, S., and Meindl, P. (2016), Supply Chain Management: strategy, planning, and operation, Global Edition (6th ed.), Pearson.

[21] Synder, R.D., Keithord, J. and Beaumont, A. (2012), Forecasting the intermittent demand for slow moving inventories: A modeling approach, "International Journal of Forecasting”, vol. 28, pp. 485-496.

[22] Pince, C. and Dekker, R. (2011), An inventory model for slow moving items subject to obsolescence, "European Journal of Operational Research", vol. 213, pp. 83-95.

[23] Randall, W.S., Nowicki, D.R., and Kulkarni, S. (2016), The perfect formula for determining the right amount of inventory.

[https://www.supplychain247.com/article/the_p erfect_formula_for_determining_the_right _amount_of_inventory] 